\title{
AN UNUSUAL CAUSE OF A CONTINUOUS MURMUR SIMULATING PERSISTEN'T DUCTUS ARTERIOSUS AND ASSOCIATED WITH OTHER CONGENITAL CARDIAC DEFECTS $S_{\vec{\circ}}^{\mathscr{\%}}$
}

\author{
BY \\ A. J. GUNNING \\ From the Nuffield Department of Surgery, Radcliffe Infirmary, Oxford
}

(RECEIVED FOR PUBLICATION SEPTEMBER 3, 1956)

A continuous murmur like that of a persistent ductus arteriosus produced by a stenosed branch of a pulmonary artery with a post-stenotic dilatation is presented in the following case. Other abnormalities included a hypoplastic left lung, atrial septal defect, ventricular septal defect, and an absent left pulmonary artery. The literature on congenital heart disease contains increasing numbers of case reports of the congenital absence of a pulmonary artery, and may be associated with either a normal heart or other congenital cardiac abnormalities. The number of cases diagnosed without operation has increased with the use of angiocardiography and cardiac catheterization. These aids may, however, on occasion be misleading, as is shown in this case. Physical and operative findings were thought worthy of reporting, not only because of the mistaken diagnosis but also because of the unusual cause of a continuous murmur simulating a persistent ductus arteriosus.

\section{CAse Report}

R.W., a boy aged 6, was referred by his doctor because of a heart murmur.

His mother had had a normal pregnancy and delivery, and the boy at birth weighed $5 \mathrm{lb}$. For the first few months feeds were taken "poorly."

The boy had always been small and slow in developing, but was active. The mother did not think that he was limited in his exertions by dyspnoea. Cyanosis had never been noticed. The boy suffered from frequent coughs and colds; the cough was productive but there had never been a haemoptysis. Just before being seen in the Out-patient Department he had complained of central chest pain, worse with coughing, and occasionally on exertion. He had had measles at the age of 4 years.

On examination he was a thin boy, small for his age, but quite active and alert. There was a suggestion of slight central cyanosis, but there was no toe or finger clubbing. The respiratory system revealed a prominent sternum and diminution of movement and air entry at the left base. In the cardiovascular sys-음 tem all pulses were palpable ; the pulse rate was $120=$ per minute with a sinus rhythm, and of normal volume $z$ and tension. The jugular venous pulse was not raised and no "a" waves were visible. Blood pressure was $\frac{\rho}{5}$ $115 / 65 \mathrm{~mm}$. Hg. The apex beat was in the fifth left $\overrightarrow{\mathscr{C}}$ intercostal space in the anterior axillary line. There $\mathcal{G}$ was a palpable pulmonary second sound, and pulsa-. V tion was visible and maximum in the third and fourth 0 left spaces anteriorly where a localized thrust felt like left ventricle. On auscultation there was a blowing systolic murmur at the apex, and the second sound was well heard together with a short rumbling $\frac{\otimes}{\odot}$ diastolic murmur. At the pulmonary area there was $\varrho$ a loud systolic murmur obscuring the first sound, and $\vec{\overrightarrow{ }}$ a very loud second sound was heard. In the aortic $\frac{3}{3}$ area a continuous machinery murmur was heard which

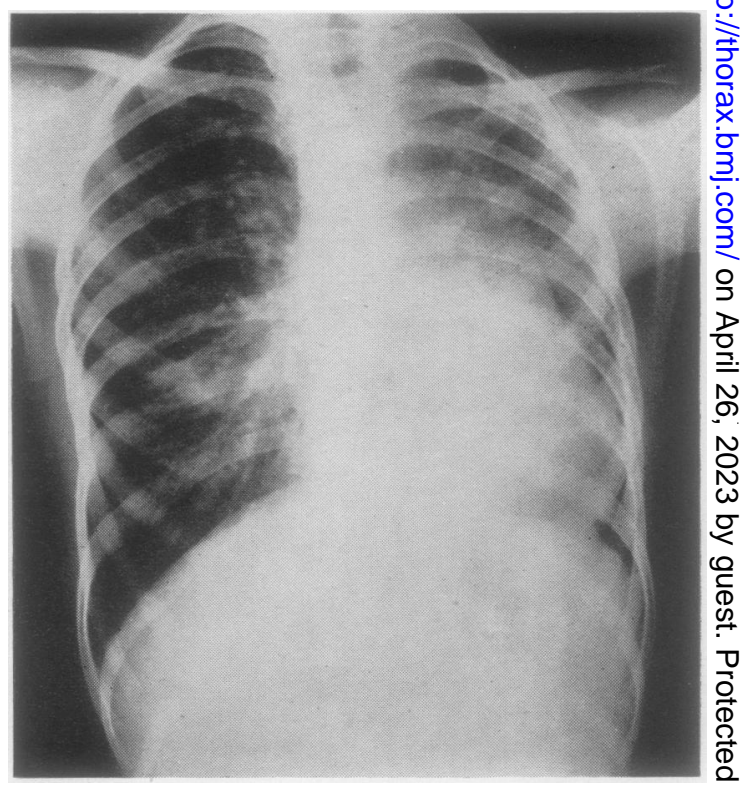

FIG. 1. - Straight radiograph of the chest showing changes described in text. 
was conducted well out into the right axilla. The second aortic sound was just heard.

A radiograph of the chest (Fig. 1) showed the mediastinum displaced and the heart rotated to the left, and the left chest appeared to be somewhat contracted. The right pulmonary vessels seemed to be considerably enlarged, and this lung field was plethoric. In view of the rotation of the heart it was very difficult to assess any abnormality in the individual chambers. The findings were suggestive of a previous left pleural effusion and some form of congenital heart disease with left-to-right shunt. When the heart was screened the aorta was seen to be right-sided. The atria appeared to be normal, but both ventricles were enlarged. The pulmonary conus was prominent and the main pulmonary vessels enlarged, particularly on the right side. The aortic pulsation was of the recoil type. The findings were in keeping with a persistent ductus with a right-sided aortic arch.

Cardiac catheterization was performed on January 7, 1955. A size 4 Cournard cardiac catheter was used and pressures recorded in the right pulmonary artery, main pulmonary artery, right ventricle, right atrium, and superior vena cava. Blood samples were taken from each of these positions and the percentage oxygen saturation determined. The pressures showed a moderate pulmonary hypertension and an increase in the percentage oxygen saturation in the right ventricle and the pulmonary artery (Table I). A No. 6

TABLE I

PRESSURES AND PERCENTAGE OXYGEN SATURATIONS

\begin{tabular}{|c|c|c|c|}
\hline Site & & $\begin{array}{l}\text { Pressure in } \\
\text { Saline (cm.) }\end{array}$ & $\begin{array}{c}\% \mathrm{O}_{2} \\
\text { Saturation }\end{array}$ \\
\hline $\begin{array}{l}\text { Right pulmonary arter } \\
\text { Main ", } \\
\text { Right ventricle } \\
\text { Sü atrium .. } \\
\text { Descendior vena cava } \\
\text { Left iliac }\end{array}$ & $\begin{array}{l}\cdots \\
\cdots \\
\cdots \\
\cdots \\
\cdots \\
\cdots\end{array}$ & $\begin{array}{l}69 \\
79 \\
53\end{array}$ & $\begin{array}{l}87 \\
86 \\
82 \\
55 \\
58 \\
98 \\
98\end{array}$ \\
\hline
\end{tabular}

cardiac catheter was substituted for the No. 4. This passed from the right ventricle to the main pulmonary artery and was thought to pass through a persistent ductus arteriosus into the aorta and into the left iliac artery. The pressure and percentage oxygen saturations were recorded and are shown in Table $I$. The catheter did not pass into the left pulmonary artery at any time.

Angiocardiography revealed no overriding of the aorta but an aortic arch on the right. It was also thought that one of the films showed the presence of a persistent ductus arteriosus on the right side.

The electrocardiograph showed right ventricular hypertrophy.

A clinical diagnosis of (1) persistent ductus arteriosus on the right, (2) ventricular septal defect, and (3) left lung abnormality, probably inflammatory in origin, was made.

Operation was performed on August 23, 1955, by Professor P. R. Allison. The right chest was opened

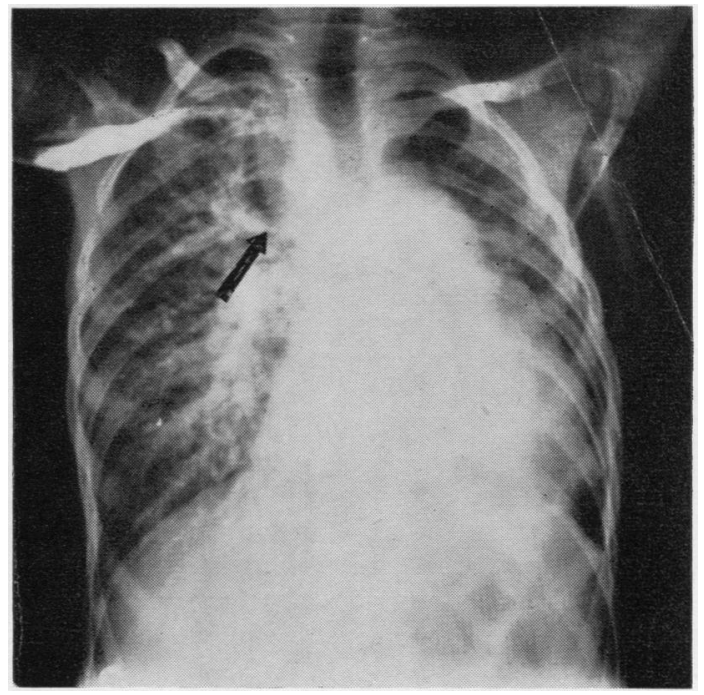

FIG. 2.-Angiocardiogram showing filling of the main pulmonary artery, right pulmonary artery and its branches with dye. The arrow indicates stenosis observed at operation.

through the third space with splitting of the sternum, the incision being carried only a small way over to the left. The left pleura was purposely opened in order to inspect the left lung. The pericardium was widely opened.

The heart was displaced to the left, the aortic arch and descending aorta being on the right side.

The main pulmonary artery was large with no left branch ; the right branch passed behind the aorta and the superior vena cavae and divided into upper and lower lobe arteries. The upper lobe artery was narrowed close to its origin and divided into three branches (Fig. 2). Of these three branches, the lower one showed a post-stenotic dilatation with weakening of the wall anteriorly so that it looked thin and blue. The thrill which was thought clinically to be from a ductus came from this dilatation and was completely abolished by gentle pressure on the vessel itself or by occlusion of the upper lobe artery leading to it. A thorough search of the right pulmonary artery and the main pulmonary artery showed that neither a persistent ductus nor an aorto-pulmonary defect was present.

A large atrial septal defect was felt after a pursestring suture had been inserted round the right auricular appendage and the finger inserted. The finger was passed through the tricuspid valve into the ventricle and no ventricular septal defect was felt, but this examination was by no means accurate.

The left lung was hypoplastic. It was represented by a diminutive structure, pale cream in colour, with a bronchus but no pulmonary artery. It could be easily inflated. There was a plexiform arrangement of minute vessels all over the hilum, and similar vessels in the adhesions between the lung and the chest 
wall. Pressures were taken at operation which confirmed the pulmonary hypertension (Table II).

TABLE II PRESSURES AT OPERATION

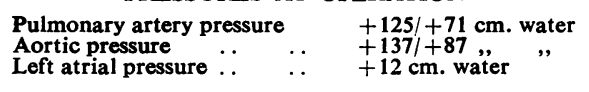

\section{Discussion}

In a review of the literature to date on congenital absence of a pulmonary artery, Emanuel and Pattinson (1956) draw attention to an absent left pulmonary artery being associated with other congenital cardiac defects, and that absence of a right pulmonary artery is found with a normal heart although there may be some abnormality in the great vessels. The findings in this case of absence of the left pulmonary artery, together with an atrial septal defect and an interventricular septal defect, agree with their observations. It would seem that this is the 47 th reported case of absence of a pulmonary artery.

While a ventricular septal defect was not palpated at operation, the cardiac catheterization studies, together with the percentage oxygen saturation values in the right ventricle and the explanation for the route taken by the catheter (see below), makes the presence of this defect certain.

The diagnosis of persistent ductus arteriosus on the right side was confidently made by several independent observers from the clinical findings alone. The diagnosis was considered to be substantiated by the catheter findings and the route taken by the catheter, which at the time was thought to have entered the aorta via a right-sided ductus. At operation no ductus was found on the right side after a long and careful dissection; nor was there any evidence of a ligamentum arteriosum on the right or from the left subclavian to the pulmonary artery, as was found by Blalock (1948) in three-fourths of the patients with a right aortic arch. From the embryology of the pulmonary arteries one would not expect to find a ductus on the right side, since that part of the sixth arch, which forms the ductus on the left, is absorbed on the right. Blalock (1948) states that in his experience with the right aortic arch the ductus has not always been on the left, and refers to the closure of a persistent ductus on the right side by operation. Where the ductus is on the right side the conventional view of development of the pul- monary arteries as shown by Rathke seems reasonable. To fit in with the current theory of Bremer (1902 and 1909), Keibel and Mall (1912), and Congdon (1922), the development of the right and left pulmonary arteries is reversed when the aortic arch is on the right, i.e., the foetal right descending aorta persists, the left being absorbed.

As no ductus was present the cardiac catheter could only have reached the descending aorta by passing through a ventricular defect and so into the aorta. Some overriding of the aorta was therefore present.

Davis, Dillon, Fell, and Gasul (1956), in a review of the literature on abnormalities simulating a persistent ductus arteriosus, make no mention of a stenosed branch of a pulmonary artery. Hurst and Schemm (1948), Ash and Murphy (1950), Baylis, Campbell, Gilmore, and Hudson (1955),

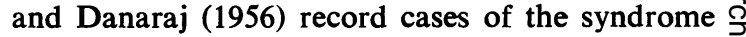
of high ventricular septal defect with aortic incompetence simulating persistent ductus arteriosus. of This was a possible diagnosis in the case described : above, and should be considered where there is a high ventricular septal defect in the presence of a continuous murmur. At operation occlusion of the stenosed pulmonary artery branch caused the $\stackrel{2}{\circ}$ continuous thrill to disappear. There is no record $\stackrel{\Phi}{\varrho}$ of a similar case in the literature.

\section{SUMmary}

A case is reported in which the stenosed branch of the right upper lobe pulmonary artery gave rise to a continuous murmur simulating a persistent ductus arteriosus. Other findings were an absent $\stackrel{x}{x}$ left pulmonary artery associated with intracardiac 0 congenital defects and hypoplasia of the left lung.

I wish to thank Dr. J. W. Brown, of the City General Hospital, Sheffield, for referring the case, and Professor P. R. Allison for permission to publish it 9 and for his help with the paper.

\section{REFERENCES}

Ash, R., and Murphy, L. (1950). J. Pediat., 37, 249.

Baylis, J. H. Campbell, M., Gilmore, H. R., and Hudson, R. (1955). Guy's Hosp. Rep., 104, 114

Blalock, A. (1948). Surg. Gynec. Obstet., 87, 385.

Bremer, J. L. (1902). Amer. J. Anat., 1, 137.

- (1909). Anat. Rec., 3, 334.

Congdon, E. D. (1922). Contr. Embryol. Carneg. Instn (No. 68), 14, 47주

Danaraj, T. J. (1956). Brit. Heart J., 18, 279.

Davis, C., Jr., Dillon, R. F., Fell, E. H., and Gasul, B. M. (1956)

Emanuel, R. W., and Pattinson, J. N. (1956). Brit. Heart J., 18, 289. (S)

Emanuel, R. W., and Pattinson, J. N. (1948). Amer. Heart J., 36, 144:

Keibel, F., and Mall, F. P. (1912). Manual of Human Embryology, $\square$ Vol. 2, p. 617. Lippincott, Philadelphia and London. 